\title{
Serum prolidase activity, oxidative stress, and nitric oxide levels in patients with bladder cancer
}

\author{
Ilhan Gecit • Mehmet Aslan • Mustafa Gunes • \\ Necip Pirincci - Ramazan Esen - Halit Demir · \\ Kadir Ceylan
}

Received: 13 October 2011/Accepted: 20 December 2011/Published online: 19 January 2012

(C) The Author(s) 2012. This article is published with open access at Springerlink.com

\begin{abstract}
Objectives Prolidase is a member of the matrix metalloproteinase family. It plays a major role in collagen turnover, matrix remodeling and cell growth. Nitric oxide (NO) regulates many processes such as collagen synthesis and matrix remodeling. Thus, NO may augment angiogenesis, tumor invasion, and metastasis. The aim of this study was to investigate total antioxidant status (TAS), malondialdehyde (MDA) and NO levels in patients with bladder cancer and to determine their relationship with prolidase activity. Design and methods Thirty-five patients with bladder cancer and 32 controls were enrolled. Serum TAS, MDA, prolidase activity and NO levels were determined.

Results Serum prolidase activity, NO levels and MDA levels were significantly higher in bladder cancer than controls (all, $P<0.05$ ), while TAS levels were significantly lower $(P<0.05)$.

Conclusions Our results show that increased prolidase seems to be associated with increased NO levels and oxidative stress along with decreased antioxidant levels in bladder cancer.
\end{abstract}

I. Gecit · M. Gunes · N. Pirincci · K. Ceylan

Department of Urology, Medical Faculty,

Yuzuncu Yil University, Van, Turkey

M. Aslan $(\square) \cdot$ R. Esen

Department of Internal Medicine, Medical Faculty,

Yuzuncu Yil University, 65400 Van, Turkey

e-mail: m.aslan301@mynet.com

H. Demir

Department of Chemistry, Faculty of Science and Art,

Yuzuncu Yil University, Van, Turkey
Keywords Bladder cancer - Nitric oxide $\cdot$ Total antioxidant status - Malondialdehyde · Prolidase activity

\section{Introduction}

Bladder cancer is a common tumor of the urinary tract (Macvicar 2000). It is the fourth most common type of cancer in men in the United States. The most common risk factors for bladder cancer are exposure to industrial carcinogens, cigarette smoking, male gender, and possibly diet (Wynder and Goldsmith 1977; Zeegers et al. 2004). Another major etiological factor is infestation by the parasite Schistosoma hematobium (Wynder and Goldsmith 1977).

Reactive oxygen species (ROS) have been implicated in the pathogenesis of various diseases, including cancers (Templar et al. 1999). There is strong evidence linking oxidative stress and bladder cancer in literature (Yalcin et al. 2004). In previous studies, it has been demonstrated that ROS are directly suggested in oxidative damage of cellular macromolecules such as lipids, proteins, and nucleic acids in tissues (Batcioglu et al. 2006). Moreover, oxidative stress can lead to tumor angiogenesis. It also has been reported that ROS can also augment tumor cell migration, increasing the risk of invasion and metastasis (Nishikawa 2008).

Nitric oxide (NO) is generated by the enzyme family of nitric oxide synthases (NOS). NO is expressed in a wide range of mammalian cells as macrophages, hepatocytes, and endothelial cells (Knowles and Moncada 1994). It is a short-lived free radical, a pleiotropic biomolecule, critical to several biological processes (Koshland 1993). NO has been suggested to play an important role in tumor biology with both facilitatory and inhibitory effects on tumor 
growth (Wolf et al. 2000). Also, NO has many implications as a potential regulatory effector for prolidase and NO may regulate the activity of metalloproteinases (MMPs; Tsuruda et al. 2004). Although prolidase is a special type of MMP, it may be also regulated by NO because it catalyzes the terminal step in matrix breakdown (Tsuruda et al. 2004).

The extracellular matrix (ECM) consists of collagens, proteoglycans, and glycoproteins. During inflammation and cancer invasion, ECM is degraded by MMPs, resulting in the release of a large amount of peptides containing proline and hydroxyproline (Surazynski et al. 2008). Among the MMPs, prolidase is a manganese-dependent cytosolic exopeptidase, and it cleaving imidodipeptides and imidotripeptides with C-terminal proline or hydroxyproline (Myara et al. 1984). Its activity has been documented in erythrocytes, leukocytes, plasma, dermal fibroblasts, the kidney, brain, heart, thymus, and uterus (Liu et al. 2007). One of the consequences of neoplastic transformation is deregulation of tissue collagen metabolism. The final step of collagen degradation is mediated by prolidase (Surazynski et al. 2008; Palka et al. 2002). Prolidase activity has been investigated in various malignant tumors including pancreas cancer (Palka et al. 2002), lung adenocarcinoma (Karna et al. 2000), breast cancer (Cechowska-Pasko et al. 2006), endometrial cancer (Arioz et al. 2009), stomach cancer (Guszczyn and Sobolewski 2004), and ovarian cancer (Camuzcuoglu et al. 2009). However, to the best of our knowledge, serum prolidase enzyme activity has not been evaluated in patients with bladder cancer.

Therefore, the aim of this study was to investigate serum total antioxidant status (TAS), malondialdehyde (MDA) and NO levels in patients with bladder cancer and to determine their relationship with serum prolidase enzyme activity.

\section{Methods}

Subjects

Thirty-five (mean age of $63.54 \pm 3.4$ ) men patients with bladder cancer were enrolled in the present a cross-sectional study. All the patients were lifetime non-smokers and free of drug, alcohol, antioxidant supplement consumption, and any metabolic disease. None of the patients had any other significant disease or malignancies except bladder cancer and only the newly diagnosed patients with no prior chemotherapeutic treatment were included in this study.

Controls consisted of 32 healthy men of age $62.76 \pm 4.8$ randomly selected from a group of healthy non-smoking volunteers with no history of previous disease, drug, antioxidant agents or alcohol consumption.
The patient and control groups were of similar socioeconomic status. As for tumor staging, 28 patients were diagnosed with non-invasive tumor (Ta-T1) where as 7 patients with invasive tumor (T2-T4). Patients were classified into three groups with respect to tumor grading where 21 patients had well differentiated (G1), 9 had intermediate (G2), and 5 had poorly differentiated (G3) tumors. The superficial urothelial papillary tumors were graded according to the 2004 World Heath Organization (WHO) grading system into low-grade and high-grade papillary neoplasms.

The study protocol was carried out in accordance with the Helsinki Declaration as revised in 2000. All participants were informed about the study protocol and the written consent was obtained from each one.

\section{Blood collection}

Following $12 \mathrm{~h}$ of fasting period, blood samples were obtained in the morning. Blood samples were collected into empty tubes and immediately stored on ice at $4^{\circ} \mathrm{C}$. The serum was then separated from the cells by centrifugation at 3,000 rpm for $10 \mathrm{~min}$. Serum samples for the measurement of prolidase activity, TAS, NO and MDA levels were stored at $-20^{\circ} \mathrm{C}$ until they were used.

\section{Measurement of total antioxidant status}

Serum TAS was determined using an automated measurement method, developed by Erel (2004). The results are expressed as mmol Trolox Equiv./l.

Measurement of serum lipid peroxidation

Serum lipid peroxidation was measured by estimating malondialdehyde (MDA) levels from serum as described by Yoshioka et al. The results are expressed as $\mathrm{nmol} / \mathrm{ml}$ (Yoshioka et al. 1979).

Determination of prolidase activity

The serum prolidase activity was determined according to the method of Myara et al. (Myara et al. 1982), based on the measurement of proline by Chinard's reagent (Chinard 1952). The results are expressed as U/l.

Measurement of serum nitric oxide

Serum $\mathrm{NO}_{2}{ }^{-} / \mathrm{NO}_{3}{ }^{-}$concentrations were determined using the Griess reaction according to Tracey et al. (Tracey et al. 1995). The results were expressed as $\mu \mathrm{mol} / \mathrm{l}$. 
Statistical analysis

All the results are expressed as means and standard deviation (mean $\pm \mathrm{SD}$ ). Non-parametric continuous variables were compared by Mann-Whitney $U$ test. Parametric variables were compared using Student's $t$ test. $P$ value less than 0.05 was considered as statistically significant. Statistical evaluation was carried out with the SPSS 11.0.

\section{Results}

The demographic and clinical data of bladder cancer and control groups are shown in Table 1. There were no statistically significant differences between bladder cancer patients and controls in respect to age and BMI (all $P>0.05$; Table 1).

Serum prolidase activity, NO levels, and MDA levels were significantly higher in bladder cancer than controls (all, $P<0.05$ ), while TAS levels were significantly lower $(P<0.05$; Table 2).

No correlation was observed between tumor grading, and serum prolidase activity, NO, MDA levels and TAS levels $(P>0.05)$.

\section{Discussion}

Collagen is major extracellular matrix component in various tissues, including kidney. It has been demonstrated that the human non-compliant bladder is characterized

Table 1 Demographic characteristics of the two groups in this study

\begin{tabular}{lccc}
\hline Parameters & $\begin{array}{l}\text { Controls } \\
(n=32)\end{array}$ & $\begin{array}{l}\text { Patients } \\
(n=35)\end{array}$ & $P$ \\
\hline Age (year) & $62.8 \pm 4.8$ & $63.5 \pm 3.4$ & $\mathrm{~ns}$ \\
Body mass index $\left(\mathrm{kg} / \mathrm{m}^{2}\right)$ & $23.42 \pm 2.14$ & $22.11 \pm 1.16$ & $\mathrm{~ns}$ \\
\hline
\end{tabular}

Values are mean $\pm \mathrm{SD}$

$n s$ non-significant

Table 2 Prolidase activity, nitric oxide, oxidative and antioxidant levels in bladder cancer and controls

\begin{tabular}{lrrr}
\hline Parameters & \multicolumn{1}{c}{$\begin{array}{l}\text { Controls } \\
(n=32)\end{array}$} & \multicolumn{1}{c}{$\begin{array}{l}\text { Patients } \\
(n=35)\end{array}$} & $P$ \\
\hline TAS (mmol Trolox Equiv./l) & $2.5 \pm 0.2$ & $1.1 \pm 0.1$ & 0.05 \\
MDA (nmol/ml) & $9.1 \pm 0.4$ & $16.8 \pm 1.6$ & 0.05 \\
NO ( $\mu \mathrm{mol} / \mathrm{l})$ & $8.1 \pm 0.8$ & $17.1 \pm 1.4$ & 0.05 \\
Prolidase $(\mathrm{U} / \mathrm{l})$ & $25.4 \pm 3.2$ & $54.8 \pm 4.3$ & 0.05 \\
\hline
\end{tabular}

Values are mean \pm SD

TAS total antioxidant status, $N O$ nitric oxide, $M D A$ malondialdehyde histologically by an increased deposition of ECM protein, especially type III collagen, in the muscle wall (Kaplan et al. 1997). Prolidase is a homodimeric iminodipeptidase that releases carboxy-terminal proline or hydroxyproline from oligopeptides. It plays a major role in collagen turnover, matrix remodeling and cell growth (Jackson et al. 1975). The primary biological function of prolidase enzyme in humans appears to involve the metabolism of collagen degradation products and the recycling of proline from dipeptides for collagen resynthesis (Surazynski et al. 2008). Moreover, it has been suggested that the prolidase enzyme activity may be a rate-limiting factor in the regulation of collagen biosynthesis (Surazynski et al. 2008).

It is well known that the breakdown of tissue barriers is catalyzed by proteolytic enzymes released from the primary tumor (Duffy 1996). The ECM composed of collagens, proteoglycans, and glycoproteins is a major barrier against the invasion of tumor cells. Therefore, a tumor progression critically depends on the breakdown of collagen and other ECM proteins (Kleiner and Stetler-Stevenson 1999). MMPs are one of the most important enzymes for the breakdown of ECM proteins. Although serum prolidase activity is well documented in certain cancers, the exact cause is still unknown (Palka et al. 2002; Karna et al. 2000; Cechowska-Pasko et al. 2006; Arioz et al. 2009; Guszczyn and Sobolewski 2004; Camuzcuoglu et al. 2009). Some authors found that increased prolidase activities in cancer such as lung (Karna et al. 2000), breast (Cechowska-Pasko et al. 2006), endometrial cancer (Arioz et al. 2009), stomach cancer (Guszczyn and Sobolewski 2004), and ovarian cancer (Camuzcuoglu et al. 2009). In contrast, Palka et al. (2002) demonstrated that prolidase activity in pancreatic cancer was decreased. On the other hand, Yoshimura et al. (2004) investigated the urinary ECM measurement in urine from patients with bladder cancer. They have found that urinary ECM levels were higher in bladder cancer groups than normal bladder groups.

In the present study, we found that patients with bladder cancer had significantly higher serum prolidase activities than healthy controls. To the best of our knowledge, serum prolidase activity has not been evaluated in bladder cancer. This is the first report investigating serum prolidase activity in patients with bladder cancer.

Prolidase and the regulation of prolidase by NO may be important in the regulation of collagen turnover. Collagen, the most abundant protein in the body, constitutes more than a quarter of total body proteins. NO has been shown to play a role in regulating collagen metabolism. High NO concentrations are associated with increased collagen biosynthesis and modification (Mei et al. 2002). Surazynski et al. 2005 demonstrate that NO stimulates prolidase activity by increasing serine/threonine phosphorylation. High concentrations of $\mathrm{NO}$ can inhibit cell growth and 
induce apoptosis in tumor cells (Cui et al. 1994). It has been suggested that NO plays an important role in tumor biology, with both tumor promoter and antitumor activity (Eijan et al. 1998). It has been reported that continuous NO production may be involved in the inflammatory process associated with the appearance of many human malignancies, including bladder cancer (O'Byrne and Dalgleish 2001). Furthermore, it has been reported that NO is elevated in the urine from patients with bladder cancer (Eijan et al. 2002). However, Bukan et al. (2003) did not observed any significant difference in serum total nitrite levels of the patients with bladder cancer and control subjects. In the present study, we found a significantly increased serum NO levels in patients with bladder cancer than in control subjects.

It is known that the harmful effects of ROS are controlled by various cellular defense systems consisting of enzymatic (catalase, glutathione peroxidase, superoxide dismutase etc.) and non-enzymatic (vitamins E, C, glutathione etc.) components (Mates et al. 1999). Epidemiological studies reveal that low levels of antioxidants are associated with an increased risk of cancer. Antioxidant depletion in the circulation may be due to the scavenging of lipid peroxides as well as sequestration by tumor cells (Sharma et al. 2007). However, if these systems are insufficient, severe metabolic malfunctions and oxidative damage to DNA may result, which, experimental studies in animals and in vitro have suggested, are an important factor in carcinogenesis (Marnett 2000). In the present study, we found a significantly decreased serum TAS levels in bladder cancer patients than in control subjects.

On the other hand, MDA, the major aldehyde end product of lipid peroxidation of membrane polyunsaturated fatty acids by free radicals, is an indicator of oxidative stress (Marnett 2000). In the present study, we found a significantly increased serum MDA levels in patients with bladder cancer than in control subjects. This is compatible with the results of two independent studies carried out by Yalcin et al. (2004) and Kaczmarek et al. (2001). Moreover, increased levels of lipid peroxidation have been reported in various malignant tumors including cervix (Beevi et al. 2007), prostate (Ozmen et al. 2006), breast (Tas et al. 2005) and lung (Gonenc et al. 2001).

Our results suggest that enhanced collagen turnover may occur in patients with bladder cancer. Increased prolidase seems to be associated with increased NO levels and oxidative stress along with decreased antioxidant levels in bladder cancer. Therefore, increased prolidase activity may, in part, play a role in the pathogenesis of bladder cancer. It is believed that the administration of antioxidant vitamins such as $\mathrm{A}, \mathrm{C}$, and $\mathrm{E}$ may be useful in preventing and treating bladder cancer.
Conflict of interest The authors declare that there are no conflict of interest.

Open Access This article is distributed under the terms of the Creative Commons Attribution Noncommercial License which permits any noncommercial use, distribution, and reproduction in any medium, provided the original author(s) and source are credited.

\section{References}

Arioz DT, Camuzcuoglu H, Toy H, Kurt S, Celik H, Aksoy N (2009) Serum prolidase activity and oxidative status in patients with stage I endometrial cancer. Int J Gynecol Cancer 19:1244-1247

Batcioglu K, Mehmet N, Ozturk IC et al (2006) Lipid peroxidation and antioxidant status in stomach cancer. Cancer Invest 24:18-21

Beevi SS, Rasheed MH, Geetha A (2007) Evidence of oxidative and nitrosative stress in patients with cervical squamous cell carcinoma. Clin Chim Acta 375:119-132

Bukan N, Sözen S, Coskun U et al (2003) Serum interleukin-18 and nitric oxide activity in bladder carcinoma. Eur Cytokine Netw 14:163-167

Camuzcuoglu H, Arioz DT, Toy H, Kurt S, Celik H, Aksoy N (2009) Assessment of preoperative serum prolidase activity in epithelial ovarian cancer. Eur J Obstet Gynecol Reprod Biol 147(1):97-100

Cechowska-Pasko M, Pakła J, Wojtukiewicz MZ (2006) Enhanced prolidase activity and decreased collagen content in breast cancer tissue. Int J Exp Pathol 87:289-296

Chinard FP (1952) Photometric estimation of proline and ornithine. J Biol Chem 199:91-95

Cui S, Reichner JS, Mateo RB, Albina JE (1994) Activated murine macrophages induce apoptosis in tumor cells through nitric oxide-dependent or independent mechanisms. Cancer Res 54:2462-2467

Duffy MJ (1996) Proteases as prognostic markers in cancer. Clin Cancer Res 2:613-618

Eijan AM, Davel K, Rueda H et al (1998) Differential nitric oxide release and sensitivity to injury in different murine mammarytumor cell lines. Int J Mol Med 2:625-630

Eijan AM, Piccardo I, Riveros MD et al (2002) Nitric oxide in patients with transitional bladder cancer. J Surg Oncol 81:203-208

Erel O (2004) A novel automated direct measurement method for total antioxidant capacity using a new generation more stable ABTS radical cation. Clin Biochem 37:277-285

Gonenc A, Ozkan Y, Torun M, Simsek B (2001) Plasma malondialdehyde (MDA) levels in breast and lung cancer patients. J Clin Pharm Ther 26:141-144

Guszczyn T, Sobolewski K (2004) Deregulation of collagen metabolism in human stomach cancer. Pathobiology 71:308-313

Jackson SH, Dennis AN, Greenberg MC (1975) Iminodipeptiduria: a genetic defect in recycling collagen; a method for determining prolidase in erythrocytes. Can Med Ass J 113(759):762-763

Kaczmarek P, Buczyński A, Niemirowicz J et al (2001) Lipids peroxidation in platelets in patients with bladder cancer treated with Mycobacterium suspension. Pol Merkur Lekarski 11:484-486

Kaplan EP, Richier JC, Howard PS, Ewalt DH, Lin VK (1997) Type III collagen messenger RNA is modulated in non-compliant human bladder tissue. J Urol 157:2366-2369

Karna E, Surazynski A, Palka J (2000) Collagen metabolism disturbances are accompanied by an increase in prolidase 
activity in lung carcinoma planoepitheliale. Int $\mathrm{J}$ Exp Pathol 81:341-347

Kleiner DE, Stetler-Stevenson WG (1999) Matrix metalloproteinases and metastasis. Cancer Chemother Pharmac 43:42-51

Knowles RG, Moncada S (1994) Nitric oxide synthase in mammals. Biochem J 198:249-258

Koshland DE Jr (1993) Molecule of the year. Science 262:1953

Liu G, Nakayama K, Awata S et al (2007) Prolidase isoenzymes in the rat: their organ distribution, developmental change and specific inhibitors. Pediatr Res 62:54-59

Macvicar AD (2000) Bladder cancer staging. BJU Int 86:111-122

Marnett LJ (2000) Oxyradicals and DNA damage. Carcinogenesis 21:361-370

Mates JM, Perez-Gomez C, de Castro IN (1999) Antioxidant enzymes and human diseases. Clin Biochem 32:595-603

Mei JM, Borchert GL, Donald SP, Phang JM (2002) Matrix metalloproteinase (s) mediate (s) NO-induced dissociation of beta-catenin from membrane bound E-cadherin and formation of nuclear beta-catenin/LEF-1 complex. Carcinogenesis 23:2119-2122

Myara I, Charpentier C, Lemonnier A (1982) Optimal conditions for prolidase assay by proline colorimetric determination: application to imminodipeptiduria. Clin Chim Acta 125:193-205

Myara I, Charpentier C, Lemonnier A (1984) Prolidase and prolidase deficiency. Life Sci 34:1985-1998

Nishikawa M (2008) Reactive oxygen species in tumor metastasis. Cancer Lett 266:53-59

O'Byrne KJ, Dalgleish AG (2001) Chronic immune activation and inflammation as the cause of malignancy. $\mathrm{Br} \mathrm{J}$ Cancer 85:473-483

Ozmen H, Erulas FA, Karatas F et al (2006) Comparison of the concentration of trace metals $(\mathrm{Ni}, \mathrm{Zn}, \mathrm{Co}, \mathrm{Cu}$, and $\mathrm{Se}), \mathrm{Fe}$, vitamins $\mathrm{A}, \mathrm{C}$, and $\mathrm{E}$, and lipid peroxidation in patients with prostate cancer. Clin Chem Lab Med 44:175-179

Palka J, Surazynski A, Karna E et al (2002) Prolidase activity disregulation in chronic pancreatitis and pancreatic cancer. Hepatogastroenterology 49:1699-1703

Sharma A, Rajjapa M, Saxena A et al (2007) Antioxidant status in advanced cervical cancer patients undergoing neoadjuvant chemoradiation. Br J Biomed Sci 64:23-27

Surazynski A, Liu Y, Miltyk W, Phang JM (2005) Nitric oxide regulates prolidase activity by serine/threonine phosphorylation. J Cell Biochem 96(5):1086-1094
Surazynski A, Donald SP, Cooper SK et al (2008a) Extracellular matrix and HIF-1 signaling: the role of prolidase. Int J Cancer 122: $1435-1440$

Surazynski A, Miltyk W, Palka J, Phang JM (2008b) Prolidasedependent regulation of collagen biosynthesis. Amino Acids 35:731-738

Tas F, Hansel H, Belce A et al (2005) Oxidative stress in breast cancer. Med Oncol 22:11-15

Templar J, Kon SP, Milligan TP, Newman DJ, Raftery MJ (1999) Increased plasma malondialdehyde levels in glomerular disease as determined by a fully validated HPLC method. Nephrol Dial Transplant 14:946-951

Tracey WR, Tse J, Carter G (1995) Lipopolysaccharide-induced changes in plasma nitrite and nitrate concentrations in rats and mice: pharmacological evaluation of nitric oxide synthase inhibitors. J Pharmacol Exp Ther 272:1011-1015

Tsuruda T, Costello-Boerrigter LC, Burnett JC Jr (2004) Matrix metalloproteinases: pathways of induction by bioactive molecules. Heart Fail Rev 9:53-61

Wolf H, Haeckel C, Roessner A (2000) Inducible nitric oxide synthase expression in human urinary bladder cancer. Virchows Arch 437:662-666

Wynder EL, Goldsmith R (1977) The epidemiology of bladder cancer: a second look. Cancer 40:1246-1268

Yalcin O, Karatas F, Erulas FA et al (2004) The levels of glutathione peroxidase, vitamins $\mathrm{A}, \mathrm{E}, \mathrm{C}$, and lipid peroxidation in patients with urothelial carcinoma of the bladder. BJU Int 93:863-866

Yoshimura R, Wada S, Matsuyama M, Hase T, Goto T, Tanaka T, Kuratsukuri K, Tsuchida K, Nakatani T (2004) Urinary extracellular matrix measurement as a reliable and cost effective diagnostic tool for bladder tumors. Int J Mol Med 13(1):127-131

Yoshioka T, Kawada K, Shimada T et al (1979) Lipid peroxidation in maternal and cord blood and protective mechanisms against activated oxygen toxicity in the blood. Am J Obster Gynecol 135:372-376

Zeegers MP, Kellen E, Buntinx F, van den Brandt PA (2004) The association between smoking, beverage consumption, diet and bladder cancer: a systematic literature review. World J Urol 21:392-401 